Portland State University

PDXScholar

1989

\title{
Types of phonological processes occurring in normal Black English speakers
}

\author{
Eileen Rella \\ Portland State University
}

Follow this and additional works at: https://pdxscholar.library.pdx.edu/open_access_etds

Part of the Linguistics Commons, and the Speech and Hearing Science Commons Let us know how access to this document benefits you.

\section{Recommended Citation}

Rella, Eileen, "Types of phonological processes occurring in normal Black English speakers" (1989). Dissertations and Theses. Paper 3920.

https://doi.org/10.15760/etd.5804

This Thesis is brought to you for free and open access. It has been accepted for inclusion in Dissertations and Theses by an authorized administrator of PDXScholar. Please contact us if we can make this document more accessible: pdxscholar@pdx.edu. 
AN ABSTRACT OF THE THESIS OF Eileen Rella for the Master of Science in Speech Communication: Speech and Hearing Sciences presented October 19, 1989.

Title: Types of Phonological Processes Occurring in Normal Black English Speakers

APRROVED BY THE MEMBERS OF THE THESIS COMMITTEE:
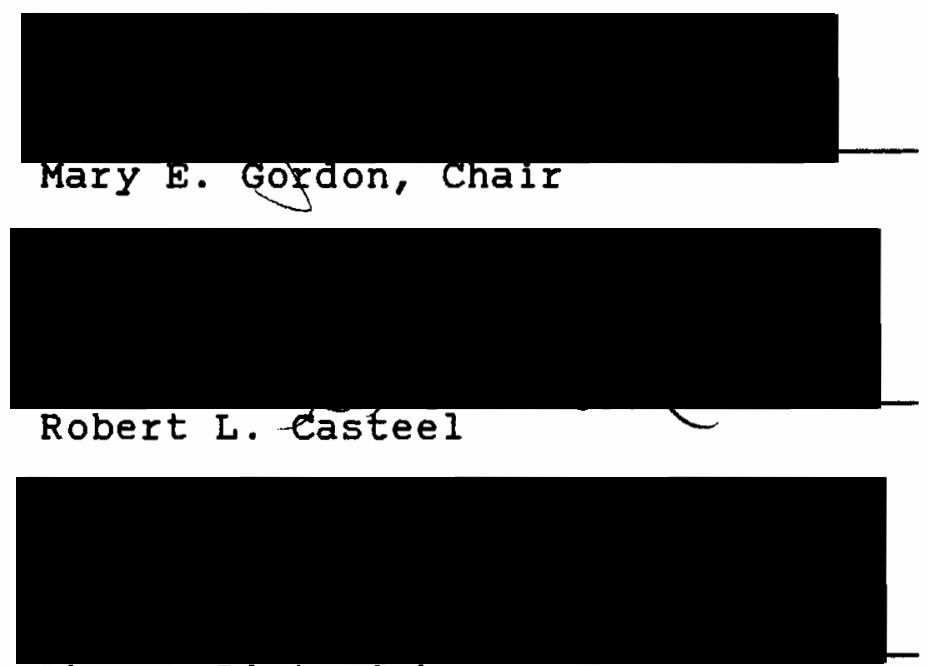

Thomas Dieterich

Black English (BE) is a rule-governed linguistic system with its own phonology, syntax, semantics, and pragmatics. BE is a dialect, not a disordered variation of standard English (SE). When compared to SE, BE phonology has been described in terms of omissions, substitutions, and additions. This study looked at normal BE speakers in Portland, Oregon and described their dialectal differences 
in terms of phonological processes.

Phonological process analysis has become a salient mode of articulation assessment. Phonological processes are the systematic sound changes that affect an entire class of sounds or sound sequences. They often occur as a normal part of the phonology of several dialects of American English. The purpose of this study was to compare the types and frequency of occurrence of phonological processes, when formally evaluated. The phonological processes that normal $B E$ speakers use must be identified in order that a speech-language pathologist can determine if the speech of a $\mathrm{BE}$ speaking child deviates from the dialectical norms.

The experimental group consisted of 15 BE speakers; the control group, $20 \mathrm{SE}$ speakers. All subjects were between 8.6 and 10.8 years of age, had normal hearing, lacked a phonetic articulation disorder, and attended the same integrated school in Portland. The Assessment of Phonological Processes-Revised (APP-R) (Hodson, 1986) was administered to both groups. The Computer Analysis of Phonological Processes (CAPP) (Hodson, 1985) was applied for the ten basic processes specified by Hodson. A manual analysis was done on the other 26 phonemic substitutions, assimilations, voicing alterations, and place shifts.

The mean occurrences of the phonological processes 
used by the BE group were compared with those used by the SE group via two-tailed t-tests for independent means. The results showed that the normal BE subjects used 8 of the 36 phonological processes significantly more frequently than SE subjects, including consonant sequence reduction, postvocalic singleton deficiency, strident deficiency, velar obstruent deficiency, liquid /1/ deficiency, nasal deficiency, vowelization, lablal assimilation, and place shifts. Although not slgniflcantly, some $B E$ speakers used liguld $/ Y /$ deficiency, stopping, and palatalization while some SE speakers used prevocalic singleton deficiency and prevocalic voicing.

Possible reasons that the results were somewhat different than expected are: 1) phonological processes may only occur in specific phonemic environments in $\mathrm{BE}$; 2 ) phonological processes may more likely occur in connected speech; 3) most of the $\mathrm{BE}$ speakers may have code switched; 4) the BE subjects attended an integrated school and therefore more likely use some $S E ;$ 5) some phonological processes may not occur in Portland's BE dialect.

The CAPP (Hodson, 1985) did not identify any of the BE speakers in this study as having a phonological disorder. Even though they used eight phonological processes more frequently than SE speakers, these processes were not used frequently enough to be targeted 
for phonological intervention. This would indicate that the $\mathrm{APP}-\mathrm{R}$ is an appropriate assessment to use with older BE speaking children in Portland, Oregon because with this test their dialectal differences are not frequent enough to warrant the label of disordered or delayed. 
TYPES OF PHONOLOGICAL PROCESSES OCCURRING IN NORMAL BLACK ENGLISH SPEAKERS

by

EILEEN RELLA

A thesis submitted in partial fulfillment of the requirements for the degree of

\author{
MASTER OF SCIENCE \\ in \\ SPEECH COMMUNICATION : \\ SPEECH AND HEARING SCIENCE \\ Portland State University \\ 1989
}


TO THE OFFICE OF GRADUATE STUDIES:

The members of the Committee approve the thesis of Eileen Rella presented October 19, 1989.

Mary E. Gordon, Chair

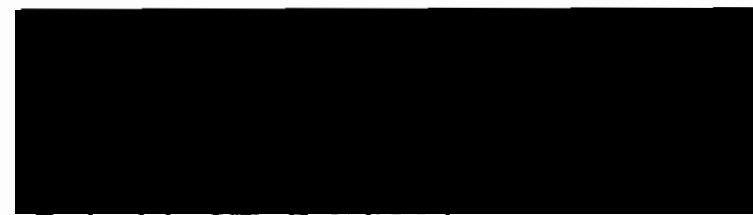

Robert $L \cdot$ castee 1

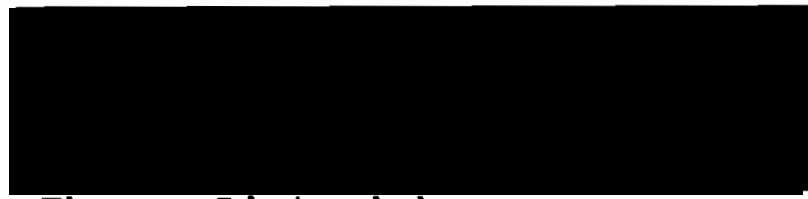

Thomas Dieterich

APPROVED BY:

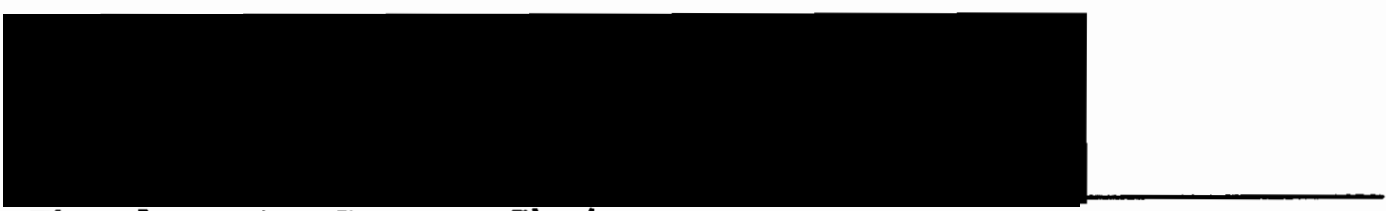

Theodore G. Grove, Chair,

Department of Speech Communication 


\section{ACKNOWLEDGEMENTS}

I want to thank my advisor, Mary Gordon, for the guidance and suggestions that she has offered me during the past two years. I am especially appreciative of her accessibility, during the summer months, as well as during the academic year.

I am thankful to Theresa Lyons, for advising me in regards to the least encumbered way into the public schools; and Betty Campbell who approved my research and facilitated the selection of subjects. Their time, support, and encouragement have been vital to the success of this project. Thank you also to the office staff of Boise-Eliot School for being helpful and courteous when I may have been disrupting their work, and to the classroom teachers who were flexible and patient when I interrupted their lessons.

I want to thank Trish Jennings and Ute Kongsbak who established reliability; Robert Casteel who read between the $l$ ines and offered valuable insight to this work; and Thomas Dieterich for his knowledge of dialectology.

And, as always, I want to thank my sister, Jo and my brother, Dan, for the love and support that they have given me, in this, and in all of my endeavors. 
TABLE OF CONTENTS

PAGE

ACKNOWLEDGEMENTS ................... i i

LIST OF TABLES..................... vi

CHAPTER

I INTRODUCTION AND STATEMENT OF PURPOSE..... 1

statement of Purpose........... 3

Definition of Terms............

I I REVIEW OF THE LITERATURE.......... 8

Black English Dialect.......... 8

speech sound Disorders..........99

Phonological Processes........... 10

Sound Changes in Black English...... 12

Segment Omission

Class Deficiency

Phonemic substitutions

Assimilation

Voicing Alterations

Place Shifts

Miscellaneous Sound Changes

in Black English

Conclusion

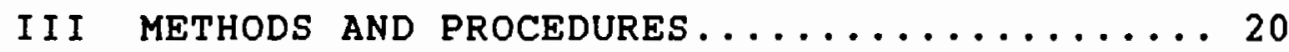

Methods.................20

Subjects

Assessment Instrumentation 
CHAP TER

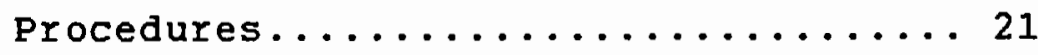

Reliability

Experimental Evaluation Procedures

Data Measurement and Analys is

IV RESULTS AND DISCUSSION .............. 25

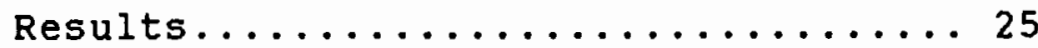

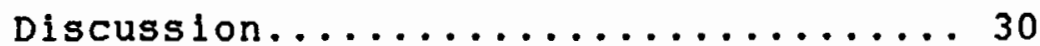

v SUMMARY AND IMPLICATIONS ............ 35

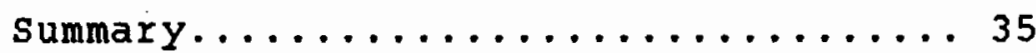

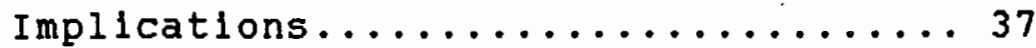

Research

clinical

REFERENCES ....................... 42

APPENDICES

A CONSENT FORM FOR SUBJECTS AND CONTROLS .... 44

B CONSENT FORM FOR SUBJECTS OVER SEVEN YEARS OF AGE.................446

C CONSENT FORM FOR RELIABILITY SAMPLE....... 48

D THE ASSESSMENT OF PHONOLOGICAL PROCESSES: ANALYSIS OF PHONOLOGICAL PROCESSES.... 50

E COMPUTER ANALYSIS OF PHONOLOGICAL PROCESSES ..................... 53 


\section{LIST OF TABLES}

TABLE

PAGE

I Means, standard Deviations and t-scores of Frequencies of Occurrence for BE and SE speakers..... 26 


\section{CHAPTER I}

\section{INTRODUCTION AND STATEMENT OF PURPOSE}

\section{INTRODUCTION}

Black English (BE) is a rule-governed linguistic system and not a disordered variation of standard English (SE). BE has its own phonology, syntax, semantics, and pragmatics (Adler \& Whitman-Tims, 1980). Phonological processes are rules that change the sound(s) in a word from the standard target production. These changes are not made on the isolated sounds, but on sounds in certain positions in a word or in specific articulatory contexts. Phonological processes occur in the early developmental stages in normal language acquisition and are generally suppressed or eliminated as a child's speech and language develop. When they persist in a standard English (SE) speaker beyond 10 years of age, speech intervention is generally warranted (Weiss, Gordon, \& Lillywhite, 1987).

Phonological processes also occur as a normal part of the phonology of several dialects of American English (Adler, 1979). The phonological processes that normal speakers of $B E$ use must be identified and understood in order that the speech-language pathologist can determine if the speech of a $B E$ speaking child deviates from the 
dialectical norm. Speech-language pathologists are restricted in their interpretation of the results of tests that assess the phonological processes of disordered BE speakers because there are no data establishing dialectal norms. Consequently, many Black children are misdiagnosed or overlooked by clinicians because of the dearth of normative data on BE phonology. When normal BE speaking children are misdiagnosed and inappropriately placed in a special education program (including speech-language intervention), they tend to learn at a slower pace then they would otherwise. When left unidentified, a genuine speech and/or language disorder may have a detrimental effect on the child's cognitive growth and development (Weddington, 1987).

To assess a child who speaks $B E$, it is necessary to have access to normative data for determining the rate of occurrence of each phonological process that is used in this dialect. When this information is available, speech-language pathologists can more accurately assess this population. The speech-language pathologist needs to be aware of the phonological processes of the normal BE speaker in order to recognize and diagnose the BE speaker who does demonstrate a delay or disorder that warrants a phonological process approach to intervention. Due to the current paucity of normative data for $B E$ speakers in the area of phonological processes, this research is a 
requisite to the clinician working with children whose primary dialect is BE. Procuring these data is essential for the assessment of preschool and school-age children whose primary dialect is $\mathrm{BE}$. Because accurate assessment is a prerequisite for effective intervention, this research is important for the delivery of articulation intervention to the preschool and school-aged children of this population who demonstrate nondialectal phonological processes in their speech.

\section{STATEMENT OF PURPOSE}

The purpose of this research was to compare the types and frequency of occurrence of phonological processes, when formally evaluated with The Assessment of Phonological Processes-Revised (APP-R) (Hodson, 1986) that are used by BE speakers in Portland, Oregon to those used by SE speakers. The construct hypothesis for this research was that $B E$ dialectical speakers between 8 and 10 years of age will use different phonological process patterns than standard English (SE) speakers in the same age group. The null hypothesis was that the types and the percentage of occurrence of phonological processes for $\mathrm{BE}$ dialectical speakers will not be significantly different from those of SE speakers. 
DEFINITION OF TERMS

The following terms are phonological processes defined operationally for purposes of this study (Hodson, $1986):$

affrication: adding a stop component to a continuant phoneme, e. g., soap $\longrightarrow /$ tsovp/.

alveolar assimilation: an alveolar phoneme replaces a nonalveolar phoneme in a word in which there is an alveolar sound, e.g., truck $\longrightarrow /$ trıt/.

backing: moving the place of articulation to a more posterior position, e. g., star $\longrightarrow / \mathrm{k} a \partial /$.

coalescence: two phonemes are replaced by a different phoneme that has characteristics of both of the replaced phonemes, e.g., spoon $\longrightarrow /$ fun/. In this example the stridency of the /s/ and the labial feature of the /p/ are retained by the substitution of $/ \mathrm{E} /$.

consonant sequence reduction: omission of any consonant in

a consonant sequence or cluster, e. g., basket $\longrightarrow$ $/ \mathrm{b} \not \mathrm{k} I \mathrm{t} /$.

deaffrication: changing an affricate to a stop or a continuant, e. g., chair $\longrightarrow / t \varepsilon \partial /$ or $/ / \varepsilon \gamma /$. (Affricates are $\left./ t \int, d /.\right)$ 
depalatalization: deleting the palatal component from a palatal phoneme, e. g., shoe $\longrightarrow / \mathrm{su} /$.

epenthesis: addition of a sound to a word, e.g., black $\longrightarrow$ $/ \mathrm{b} \partial \mathrm{le} \mathrm{k} /$.

fronting: the target phoneme is substituted by a phoneme that is produced at a more forward place of articulation than the target would have been, e. g., gum $\longrightarrow / \mathrm{d} \wedge \mathrm{m} /$.

glide deletion: a glide phoneme is omitted or substituted by a nonglide phoneme, e.g., watch $\longrightarrow / \mathrm{bat} \int /$. (Glide phonemes are $/ w, j /$. )

gliding: a glide replaces another sound, e. g., rock $/ \mathrm{wak} /$. (Glide phonemes are $/ w, j /$.

labial assimilation: a labial phoneme replaces a non-labial phoneme in a word in which there is a labial phoneme, e. g., soap $\longrightarrow /$ wov p/.

liquid deletion: a liquid is omitted or substituted by another phoneme, e. g., candle $\longrightarrow / \mathrm{k} \not$ ndo/ or rock /wak/. (Liquid phonemes are / $/ \mathrm{l} / \mathrm{l}$ )

metathesis: a transposition of phonemes or syllables within a word, e.g., mask $\longrightarrow / \mathrm{m} \not \mathrm{ks} /$.

migration: one phoneme is moved to a different place in the word, e. g., smoke $\longrightarrow /$ movks/.

nasal assimilation: a nasal sound replaces a nonnasal sound in a word in which there is a nasal sound, e. g., thumb $\longrightarrow / \mathrm{n} \wedge \mathrm{m} /$. 
nasal omission: a nasal phoneme is omitted or substituted by a nonnasal phoneme, e. g., nose $\longrightarrow / d o z /$. Nasal phonemes are $/ \mathrm{n} /, / \mathrm{m} /, / \eta /$.

palatalization: a palatal component is substituted for

a non-palatal sound, e. g., soap $\longrightarrow / \int 0 \mathrm{vp} /$.

place shift: the place of articulation changes, while the manner and voicing remain the same, e. g., mouth $\longrightarrow /$ ma $v f /$.

postvocalic devoicing: an unvoiced consonant replaces a voiced consonant that follows a vowel, e. g., page $\longrightarrow$ peI tf 1 .

postvocalic singleton omission: omission of the consonant that ends a syllable, e. g., basket $\longrightarrow / \mathrm{b} \not s k I /$. postvocalic voicing: a voiced consonant replaces an unvoiced consonant that follows a vowel, e.g., ate $\longrightarrow /$ ed $/$.

prevocalic devoicing: an unvoiced consonant replaces a voiced consonant that precedes a vowel, e. g., boats $\longrightarrow$ /po vts/.

prevocalic singleton omission: omission of a consonant that initiates a syllable, e. g., basket $\longrightarrow$ / xskIt/.

prevocalic voicing: a voiced consonant replaces an unvoiced consonant that preceeds a vowel, e. g., page $\longrightarrow /$ be I d $/$. 
stopping: a stop consonant is substituted for a continuant, e. g., feather $\longrightarrow / f \varepsilon d \chi /$. stops are $/ p, b, t, d, k, g /$.

stridency deletion: strident sound is totally omitted or is substituted by a nonstrident phoneme, e. g., shoe $\longrightarrow /$ tu/. (strident phonemes are $/ \mathbf{s}, \mathbf{z}, \int, 3$, $\left.t, a_{3}, t, v /.\right)$

syllable reduction: the omission of a syllable in the target word, e.g., basket $\longrightarrow / \mathrm{b} \not /$.

velar assimilation: a velar sound replaces a nonvelar sound in a word in which there is a velar phoneme, e.g., truck $\longrightarrow / \mathrm{kr} \wedge \mathrm{k} /$.

(Velar phonemes are $/ \mathrm{g}, \mathrm{k} /$. )

velar obstruent deletion: a velar stop is omitted or substituted by a nonvelar sound, e. g., candle $\longrightarrow$ $/ \mathrm{t} \mathscr{\mathrm { ndl }} /$. (Velar obstruent phonemes are $/ \mathrm{g}, \mathrm{k} /$. ) vowelization: replacing a consonant with a vowel, e. g., boats $\longrightarrow /$ bovt $\partial /$. 


\section{CHAPTER II}

\section{REVIEW OF THE LITERATURE}

In this chapter, Black English, two types of speech sound disorders, and phonological processes that are assessed in The Assessment of Phonological Processes-Revised (APP-R) (Hodson, 1986) are described. The sound changes that occur in BE are then described.

\section{BLACK ENGLISH DIALECT}

BE is a dialect or a "linguistic code" (Shames \& Wiig, 1986, p.396) that is used primarily by working class Blacks in the United states. A dialect is a specific form of a language that is different in the pronunciation, semantics, and idiomatic use of words from the standard form of the language. However, a dialect is not different enough from other dialects or from the standard form to be considered a distinct language (Nicolosi, Harryman, \& Kresheck, 1989). The structure and use of a dialect is determined by social, ethnic, geographic, and linguistic influences. A primary dialect is the dialect that one has learned to speak in one's home environment and continues to use in social interaction with one's family and peers (Shames \& M11g, 1986). 
SPEECH SOUND DISORDERS

speech sound disorders can be classified as either phonetic or phonemic. Phonetic disorders are due to faulty planning and/or inaccurate execution of motoric movements. Chlldren with these disorders seemingly know the phonetic rule system of English, but do not execute this system in the production of all their speech sounds. It appears as though they are unable to use, or program, the articulators or do not have the motoric capability necessary for normal speech. Children with phonetic disorders are usually consistent with their errors and seldom or never say the sound correctly, although this description of consistency does not apply to dyspraxia which is also considered to be a phonetic disorder (Weiss, Gordon, \& L11lywhite, 1987).

Conversely, phonemic (sometimes referred to as phonologic) disorders occur because of "disturbances in (the) organization or representation of linguistic units and rules" (Meltus \& Welnberg, 1983, p.121). Phonologlcal processes describe systematic sound changes that affect an entire class of sounds or sound sequences and tend to simplify the adult target sound (Weiss, Gordon, \& Lillywhite, 1987). A child with a phonologlc disorder demonstrates speech sound errors that can be grouped into patterns of misarticulations (Meitus \& Weinberg, 1983). These patterns include changes in syllable structure, 
voicing, manner of production, or place of articulation.

\section{PHONOLOGICAL PROCESSES}

Several assessment instruments are available for the ldentification of phonological processes (Hodson, 1986; Ingram, 1976; Khan \& Lewis, 1986; Shriberg \& Kwiatowski, 1980; Weiner, 1979). None of these tests provide norms for $\mathrm{BE}$ speakers; consequently, these chlldren may be penallzed for responses that are actually correct in their dialect. Without dialectic norms, the cliniclans are not easily able to interpret the performance of Black children on standardized tests.

There are language tests that either have $B E$ norms, or are written specifically for BE dialect. The structured Photographic Expressive Language Test-Preschool (SPELT-P) (Werner \& Kresheck, 1983) does address the differences in the language of $B E$ speakers from $S E$ speakers. Correct responses and scoring instructions are given for both dialects. The screening Kit of Language Development (SKOLD) (Bliss \& Allan, 1983) and the Black Enqlish Sentence Scoring (BESS) (Nelson, 1983) are other tests to assess the language of $\mathrm{BE}$ speakers. However, there are no valid standardized tests to assess the phonology of BE speakers (Vaughn-Cook, 1983). There is a need in this field for more assessment tools that are more serviceable to a speech-language pathologist by providing 
such information.

As previously stated, there are several phonological processes assessments available. Different authors may have different approaches to phonological processes analysis and they tend to define the processes somewhat differently. This researcher will define phonological processes as they are described by Hodson (1986) whodivides phonological processes into five categorles: segment omissions, class deficiencies, phonetic substitutions, assimilations, and volcing alterations.

A segment omission is the deletion of a sound or sounds; they are not substituted by another sound. segment omissions include syllable reduction, consonant sequence reduction, prevocalic singleton omission, and postrocalic singleton omission. Class deficiencies occur whenever a class of phonemes is omitted or substituted for another class of phonemes. They include the deletion of a strident, velar obstruent, nasal, liquid, or glide.

In the category of phonemic substitutions, a phoneme is substituted by another phoneme of any class. Phonemic substitutions include epenthesis, metathes1s, migration, coalescence, vowelization, gliding, and stopping. Assimilation is the replacement of one phoneme by another phoneme; this replacing phoneme has characteristics similar to still another phoneme in the target word. Hence, in assimilation, the sounds in the word become more 
similar. It is assumed that the sound change occurs because of the influence of this third phoneme. Assimilations are categorized by the feature that is added to the changed sound. There are labial, velar, nasal, and alveolar assimilations.

In voicing alterations, voicing is either added to or deleted from the target sound. The alterations are defined by their position in a word. This category includes postrocalic voicing and devoicing, and prevocalic volcing and devolcing.

A place shift is a minimal change in the place of articulation. This phonological process does not reduce intelligibility to any great extend. It includes sibilant distortions, e. g., lateral lips, and replacement of Interdental phonemes with anterior stridents.

\section{SOUND CHANGES IN BLACK ENGLISH}

This section will include a discussion of some of the sound changes in BE from a phonological processes perspective. Sounds within words in BE often differ from sounds within words in SE. BE has the same 45-48 sounds as SE; however, these sounds in BE have a "different pattern of distribution" (Smitherman, 1977, p. 17) when compared with SE. Suprasegmental components of speech, such as rhythm, inflection and stress patterns, will not be discussed here as they are not within the scope of this 
research. Because the $B E$ dialect varies from one area of the United states to another area, no one set of morphological rules applies to every BE speaker. It appears that the authors (Adler, 1971, 1979; Dillard, 1972; Hodson, 1986; Khan \& Lewis, 1986; Mallory \& Chapman, 1978; Seymour \& Miller-Jones, 1981; Smitherman, 1977) cited here are describing $B E$ speakers in their own geographical areas; consequently, all of the sound changes described here may not be true of $B E$ speakers in Portland, oregon. In most of the literature describing sound changes within $\mathrm{BE}$, the sound changes are described as substitutions and omissions rather than as phonological processes. This reviewer will describe these sound changes using the categories of phonological processes as described above.

Segment omission

In reviewing the literature, three types of segment omission were noted by this researcher, 1. e., syllable reduction, consonant sequence reduction, and postvocalic singleton deletion. As stated in the definition of terms, syllable reduction is the omission of a syllable from a word. In BE, "brother", in common parlance, is shortened to "bro" which is an example of syllable reduction. BE speakers often reduce consonant clusters to a slngle consonant (Adler, 1979); "men/meant", "hole/hold", "pass/past" are examples of consonant sequence reduction. 
Cluster reduction also occurs in young SE speakers. The frequency of occurrence of this phonological process has been shown to decrease between 24 and 36 months of age in both BE and SE speakers; however, it decreases to a lesser extent in BE speakers and continues to occur in adult BE speakers (Mallory \& Chapman, 1978).

A frequent omission in BE is that of the last sound in a word, e.g., "hood" becomes "hoo" and "will" becomes "wi" (Smitherman, 1977, p.17). This pattern can be described as postrocalic singleton omission.

\section{Class Deficiency}

In the literature, this researcher found examples of three types of class deficiencies, i. e., stridents, liquids, and nasals. Rules of $\mathrm{BE}$ grammar dictate the omission of $-s$ that occurs in $S E$ for regular third person singular and possessive forms. Thus, "run/runs" and "John/John's" (Adler, 1971, 1979) could be described as stridency deletion.

BE speakers frequently omit $/ r /$ and $/ I /$ when in the medial and final position (Seymour \& Seymour, 1981; Smitherman, 1977). More will be sald about liquid /r/ and $/ 1 /$ deficiency in the following section.

Vowels before nasals may be nasalized and the nasal consonant itself dropped (Adler, 1979; Seymour \& Miller-Jones, 1981). This is a deletion of the nasal class. 
Phonemic Substitutions

Thirteen phonemic substitutions were described in the previous section of this chapter. Two were found in the literature describing BE speakers: vowelization and stopping.

As stated above, BE speakers frequently omit $/ r /$ and $1 /$ when in the medial or final position (smltherman, 1977). Occasionally, these liquids are replaced by $/ \wedge /$, e.g., "steauh/steal" and "heuhp/help" (Seymour \& Miller-Jones, 1981). This can be classifled as vowelization as well as liquid class deficiencles. If postrocalic singleton omission also occurs, "help" would become "heuh".

Substitutions are a common occurrence in $\mathrm{BE}$ phonology. Volced fricatives that proceed rasals are often stopped, e.g., "idn't/isn't" and "sebm/seven" (Adler, 1979). This would be an example of the phonological process called stopping.

\section{Assimilation}

The I1terature cited examples of two types of assimilation. As stated earlier, it is presumed that the sound change is influenced by another sound in the target word that may or may not be changed itself.

In the substitutions of $v / \mathcal{W}$ and $f / \theta$, the voicing feature and manner remain unchanged and the place of articulation changes. In "bave/bathe" and "baf/bath" 
(Smitherman, 1977), the one consonant in the target word may influence a second consonant so that both consonants are produced at a "similar place of articulation" (Khan \& Lewis, 1986 , p.5). In these examples, the assimilation is labial.

The medial volced / $/ /$ in a polysyllabic word is frequently substituted by $/ v /$ which is also a volced sound, e.g., "mover/mother" (Adler, 1979; Dillard, 1972). This is another example of labial assimilation. In this case, the sound changes from a lingua-dental to a lablo-dental place of articulation; the manner of production does not change with this substitution since both /V/ and / み/ are fricatives.

The final unvolced $/ \theta /$ is often substituted by $/ f /$, also an unvoiced fricative, e.g., "mouf/mouth" (Dillard, 1972; Seymour \& Miller-Jones, 1981). As with the previous example of labial assimilation, the place of articulation changes from lingua-dental to labio-dental and the fricative manner of production and volcing remain unchanged.

Changes in place of articulation that occur in BE are often characterized as result of assimilation. The initial volced / $み /$ is frequently substituted by /d/ which is also a volced sound, e.g., "dis/this" (Dillard, 1972; Smitherman, 1977). The sound changes from a lingua-dental to a lingua-alveolar place of articulation. 
This is an example of alveolar assimilation. The lingua-alveolar placement of the $/ \mathrm{s} /$ in the target word presumedly affects the placement of the first phoneme in the word. The manner of production changes from a fricative to a stop, which is classified as stopping as well.

\section{Voicing Alterations}

The researcher found several examples of one phonological process in the category of volcing alterations, postvocalic devoicing. Postvocalic devoicing occurs with /b/, /d/, /g/, e. g., "cap/cab" and "but/bud" (Seymour \& seymour, 1981). Pairs of words that are affected by this devoicing rule are distinguished from each other by prolongation of the vowel before the substituted stop (Seymour \& Miller-Jones, 1981). Therefore, when BE speakers say "but" they often lengthen the vowel / u/ when they are talking about the shoot of a leaf "bu:/bud" and not lengthen the vowel/u/ when they are using the conjunction "bu/but" (Adler, 1979).

The plural form of -es is not produced with the $/ z /$ sound, but with the /s/ sound (Dillard, 1972). This is another example of postvocalic devoicing. Pluralizing a noun whose final consonant has been deleted results in a word that sounds quite different from the SE pronunciation of that word. In pluralized forms of nouns that end in double consonants, BE speakers add -es for plural. Thus 
the singular form of "wasp" becomes "was" and when it is then pluralized, it becomes "wasses" (Smitherman, 1977).

\section{Place Shift}

The most frequent example of place shifts that BE speakers use is the replacement of interdental phonemes with anterior stridents, e. $g ., / \theta$, $/ \longrightarrow / f, v, s, z /$. Many of these are dicussed in the section, Assimilation. Specific examples are "baf/bath" (Smitherman, 1977), "mover/mother" (Adler, 1979; Dillard, 1972), and "dis/this" (Dillard, 1972; Smitherman, 1977).

Miscellaneous Sound Changes in Black English

In BE speech, initial /st/ and /sk/ have a "slightly different articulation from that of SE" (Dillard, 1972, p.311). Dillard neither describes this difference nor gives lexical examples of it. BE has phonological aspects that $\mathrm{SE}$ and other varieties of English lack. Bilabial fricatives / $\beta$ / are found in some varieties of $B E$ (Dillard, 1972).

Conclusion

No dialect of English is a disorder (Vaughn-Cooke, 1983). In descrlbing the differences between $B E$ and $S E$ phonology, the author does not intend to imply that BE phonology is incorrect. She has labeled some of the traits of BE phonology as phonological processes because these features, which differ from the SE spoken by most 
speech-language pathologists, fit the description that Hodson (1986) gives for phonological processes. 
CHAPTER III

METHODS AND PROCEDURES

METHODS

\section{$\underline{\text { subjects }}$}

The experimental group was composed of 15 BE speakers who met the following criteria: (a) between 8.6 and 10.8 years of age, with a mean age of 9.5 (b) passing a $20 \mathrm{~dB}$ unilateral audiometric screen, and (c) absence of phonetic articulation disorder or delay. The subjects were between 8 and 10 years of age because by this age, most children have acquired normal adult speech patterns (Weiss, Gordon, \& Lillywhite, 1987). A unilateral pure tone audiometric screening test was administered at $20 \mathrm{~dB}$ HL for the frequencies of $500,1000,2000$, and $4000 \mathrm{~Hz}$. The researcher conferred with the school speech-language pathologist who has had clinical experience with this population to determine the status of the potential subjects' articulation.

The control group consisted of 20 normal SE speakers from the same school as the experimental group, between 8.3 and 10.9 years of age with a mean age of 9.5. The same selection criteria were used for this group as for the experimental group. A consent form (Appendix A) was 
signed by the primary caregiver of each experimental and control subject and a consent form (Appendix B) was signed by each child who participated in this study.

\section{Assessment Instrumentation}

The Assessment of Phonological Processes-Revised

$(\underline{A P P}-\mathrm{R})$ (Hodson, 1986) was used to assess the phonological patterns of the experimental and control subjects. The test manual does not report reliability or validity data.

\section{Computer Analysis of Phonological Processes (CAPP)}

(Hodson, 1985) was used to analyze the omissions and class deficiences in the APP-R, including syllable reduction, prevocalic singletons, postvocalic singletons, consonant sequences, stridency deletion, velar deletion, liquid / / / and $/ r /$ deletion, nasal deletion, and glide deletion. The researcher manually analyzed the remaining phonological processes assessed by the $\underline{A P P}-R$. This analysis states the percentages of occurrence for these phonological processses. It also states whether or not the testee is a candidate for a phonological approach to intervention.

\section{PROCEDURES}

\section{Reliability}

Interrater reliability was established between the researcher and another second-year graduate student with a major in Speech-Language Pathology. Both had received instruction in the administration of the APP-R 
and had administered and analysed it.

To establish interrater reliabilty, six children between 3 and 5 years of age were chosen randomly. A consent form (Appendix C) was signed by the primary caregiver of each of these children. Three of the children were $S E$ speakers and three were $B E$ speakers. This age group was used to determine reliability because there was an increased likelihood that they woulduse misarticulations, providing the judges with more items to score.

The researcher administered the $\underline{A P P-R}$ to these preschoolers per manual instructions in the presence of the other judge. The test administrations were tape recorded. Both judges scored the tests individually at the time of testing and later listened to the tape recording as needed to fill in the gaps or to confirm responses. The judges each transcribed the responses onto the APP-R test forms (Appendix D) and scored the test individually. Interrater reliability scores ranged from .80 to 1.0 for the number of occurrences for each process. Intrarater reliability was established by rescoring some items from each of the six tests. Fifty ltems were chosen by another second year graduate student using a random number table. The second graduate student picked one of the six responses for each of the 50 items on the APP-R. After an interim of two weeks, intrarater 
reliability of .83 to 1.0 was established for each process by rescoring the transcript of each response.

\section{Experimental Evaluation Procedure}

Each subject was administered The Assessment of

Phonological Processes-Revised (APP-R) (Hodson, 1986) as instructed in the examiner's manual. When the subject did not name a stimulus item or used a different label, the researcher named it, then said, "Repeat that please." The subjects' responses were tape recorded with an external microphone suspended from the child's neck, approximately 5 inches from the mouth. When necessary, the tape recording was used for later confirmation of the transcription. A complete phonetic transcription of the subjects' responses was recorded on the test form as the child identified the objects. A phonological processes analysis was conducted on each response.

The Computer Analysis of Phonological Processes (CAPP) (Hodson, 1985) (Appendix E) was applied for the following phonological processes: syllable reduction, prevocalic singletons, postvocal singletons, consonant sequences, strldents, velars, liquid /1/, liquid /r/, nasals, and glides. A manual analysis was done on the phonemic substitutions, assimilations, voicing alterations, and place shifts. 
Data Measurement and Analysis

Percentage of occurrence for each of the ten basic phonological processes was calculated and the mean percentages for each group were compared. The frequency of occurrence was calculated for the remainder of the phonological processes. The mean for each of these processes for each group were compared. To determine if a statistically significant difference exists between the means of the $B E$ speakers and $S E$ speakers, a two-tailed t-test for independent means was computed according to the procedure described by Bruning and Kintz (1987). 
CHAPTER IV

RESULTS AND DISCUSSION

RESULTS

The stated purpose of this study was to compare the types and frequencies of occurrence of phonological processes that are used by $B E$ speakers in Portland, oregon to those used by SE speakers. The null hypothesis was that the types and frequencies of occurrence of phonological processes for BE dialectical speakers will not be significantly different from those of SE speakers. One-word samples were collected from children between 8.3 and 10.9 years of age, using the APP-R (Hodson, 1986). These samples were collected from $20 \mathrm{SE}$ speakers and $15 \mathrm{BE}$ speakers from the same Portland public school. Two-tailed t-tests were computed to compare the differences between the two groups. Table I shows the means, standard deviations, and $\underline{t}$-scores of the phonological processes that were used by $B E$ and $S E$ speakers.

There were statistically significant differences between the $\mathrm{BE}$ and $\mathrm{SE}$ speakers on the frequency of occurrence for eight phonological processes; the BE speakers used all of these processes more frequently than the SE speakers. These phonological process were 
TABLE I

MEANS, STANDARD DEVIATIONS AND $t$-SCORES

OF FREQUENCIES OF OCCURRENCE

FOR BE AND SE SPEAKERS

\begin{tabular}{|c|c|c|c|c|c|}
\hline $\begin{array}{l}\text { Phonological } \\
\text { t-score } \\
\text { Processses }\end{array}$ & $\begin{array}{l}\mathrm{X} \\
\mathrm{BE}\end{array}$ & $\begin{array}{r}S D \\
\text { speakers } \\
\end{array}$ & $\begin{array}{ll}x \\
S E\end{array}$ & $\begin{array}{r}\mathrm{SD} \\
\text { speakers } \\
\end{array}$ & \\
\hline Affric'n & 0 & 0 & 0 & 0 & $\mathrm{n} / \mathrm{a}$ \\
\hline AlveAssim & 0 & 0 & 0 & 0 & $\mathrm{n} / \mathrm{a}$ \\
\hline Backing & 0 & 0 & 0 & 0 & $\mathrm{n} / \mathrm{a}$ \\
\hline Coalescence & 0 & 0 & 0 & 0 & $\mathrm{n} / \mathrm{a}$ \\
\hline Consseg\# & 6.4 & 4.3 & 16 & 2.1 & $4.325 *$ \\
\hline Deaffric'n & 0 & 0 & 0 & 0 & $\mathrm{n} / \mathrm{a}$ \\
\hline Depalat'n & 0 & 0 & 0 & 0 & $\mathrm{n} / \mathrm{a}$ \\
\hline Epenthesis & 0.6 & 0.3 & 0 & 0 & 1.160 \\
\hline Fronting & 0 & 0 & 0 & 0 & $\mathrm{n} / \mathrm{a}$ \\
\hline GI ideDel & 0 & 0 & 0 & 0 & $\mathrm{n} / \mathrm{a}$ \\
\hline Gliding & 0 & 0 & 0 & 0 & $\mathrm{n} / \mathrm{a}$ \\
\hline GlotRe & 0 & 0 & 0 & 0 & $\mathrm{n} / \mathrm{a}$ \\
\hline LabialAssim & 0.9 & 0.8 & 0.1 & 0.2 & $4.708 *$ \\
\hline $\mathrm{Lig} / 1 / \mathrm{Del} \#$ & 7.8 & 4.6 & 0.4 & 2.0 & $6.347 *$ \\
\hline $\mathrm{Lig} / \mathrm{I} / \mathrm{Del} \#$ & 0.6 & 1.8 & 0 & 0 & 1.703 \\
\hline
\end{tabular}


TABLE I

MEANS, STANDARD DEVIATION AND t-SCORES

OF FREQUENCIES OF OCCURRENCE

FOR BE AND SE SPEAKERS

(continued)

\begin{tabular}{llllll}
\hline $\begin{array}{l}\text { Phonological } \\
\text { t-score }\end{array}$ & $\mathrm{x}$ & $\mathrm{SD}$ & $\mathrm{x}$ & \multicolumn{2}{l}{ SD } \\
Processes & BE & speakers & $\mathrm{SE}$ & speakers \\
\hline Metathesis & 0 & 0 & 0 & 0 & $\mathrm{n} / \mathrm{a}$ \\
Migration & 0 & 0 & 0 & 0 & $\mathrm{n} / \mathrm{a}$ \\
Nasalassim & 0 & 0 & 0 & 0 & $\mathrm{n} / \mathrm{a}$ \\
Nasaldel\# & 4.2 & 3.2 & 0 & 0 & $5.936 *$ \\
Palatizat'n & 0.1 & 0.3 & 0 & 0 & 1.044 \\
Placeshift & 0.9 & 0.8 & 0.1 & 0.2 & $4.708 *$ \\
Postvocsing\# & 3.9 & 6.5 & 0 & 0 & $2.708 *$ \\
Post-Voicing & 0 & 0 & 0 & 0 & $\mathrm{n} / \mathrm{a}$ \\
Prevocsing\# & 0 & 0 & 0.1 & 0.4 & 0.863 \\
PretVoicing & 0 & 0 & 0.1 & 0.2 & 0.863 \\
Pre-Voicing & 0 & 0 & 0 & 0 & $\mathrm{n} / \mathrm{a}$ \\
Reduplica'n & 0 & 0 & 0 & 0 & $\mathrm{n} / \mathrm{a}$ \\
SiblantDist & 0 & 0 & 0 & 0 & $\mathrm{n} / \mathrm{a}$ \\
Stopping & 0.1 & 0.4 & 0 & 0 & 1.703 \\
StridentDel\# & 1.1 & 4.3 & 0.1 & 0.4 & $2.180 *$ \\
SyllabDel & 0 & 0 & 0 & 0 & $\mathrm{n} / \mathrm{a}$
\end{tabular}


TABLE I

MEANS, STANDARD DEVIATIONS AND $t$-SCORES

FOR BE AND SE SPEAKERS

(continued)

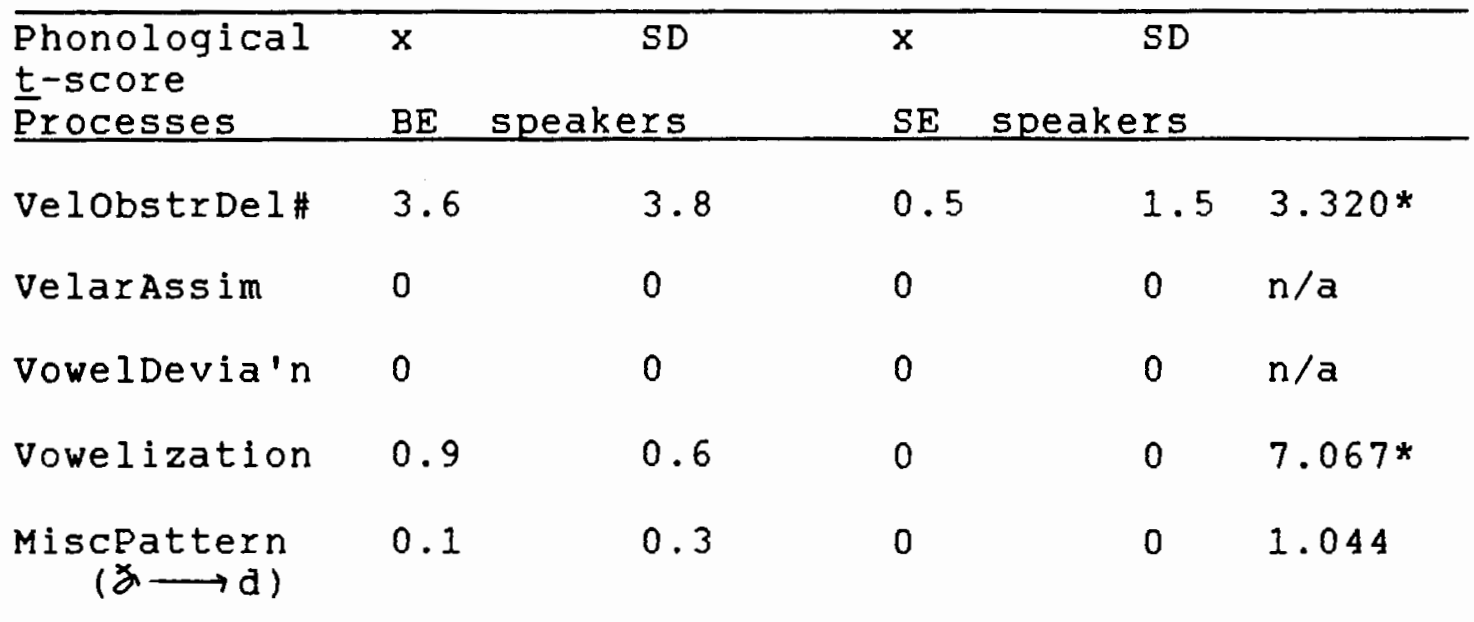

* Significant at or beyond 0.05 level of confidence.

\# Percentages of frequencies of occurrence. 
consonant sequence reduction, postvocalic singleton deficiency, strident deficiency, velar obstruent deficiency, liquid / $1 /$ deficiency, nasal deficiency, vowelization, labial assimilation, and place shifts.

There were no statistically significant differences between $B E$ and $S E$ speakers on the frequency of occurrence for the remaining 28 phonological processes. Some BE speakers used liquid $/$ r/ deficiency (e. g., chair $\longrightarrow$ $/ f \varepsilon \partial / 1$, stopping (e.g., glove $\longrightarrow / g l \wedge b /$ ), and palatalization (string $\longrightarrow / \int \operatorname{tr} I \mathrm{~g} /$ ), but none of the SE speakers did. Only some of the SE speakers used prevocalic singleton deficiency (e. g., television t $\varepsilon \cdot \partial \mathrm{vI} z \partial \mathrm{n} /$ ) and prevocalic voicing (e. g., sweater $\longrightarrow / s w \in d \gamma / /$. The following phonological processes were not used by any of the $B E$ or SE speakers in this research: syllable reduction, glide deficiency, glottal replacement, fronting, backing, gliding, vowel deviations, metathesis, migration, reduplication, coalescence, affrication, deaffrication, depalatalization, prevocalic devoicing, postrocalic devoicing, sibilant distortions, and nasal, velar, and alveolar assimilations. 


\section{DISCUSSION}

It is of interest to note how the results of this study compared with the results that the author anticipated after a review of the literature. As stated in Chapter II, BE speakers tend to use the following phonological processes: consonant sequence reduction, postrocalic singleton deficiency, stridency deletion, nasal deficlency, vowelization, labial assimilation, deficiency of liquid /l/ in the medial position, syllable reduction, stopping, alveolar assimilation, postrocalic devoicing, and deficiency of liquid / $/$ in the medial position. The results of this study showed that $B E$ speakers in Portland, oregon used 7 of these 12 expected phonological processes; these phonological processes are the first 7 isted above.

Some of the BE subjects in this sample did use liquid $/ r /$ deficiency and stopping, but not significantly more than the SE speakers. They did not use syllable reduction or postrocalic devoicing at all.

There are $\mathbf{s} 1 \times$ possible reasons for these results. First, a sound change that appears to be a phonological process per the APP-R, may not be a phonological process when the sound change occurs in words other than the target words. This researcher labelled $v / \not{F}$ and $f / \theta$ substitutions reported in the literature, as labial assimilation, as well as place shifts. These labels were 
appropriate for the examples that were given for the substitutions (mover/mother and baf/bath). It is also appropriate for the words "mouth" and "toothbrush", which are APP-R target words. Both these words contain labial sounds; therefore, in these two cases the $\mathrm{v} / \%$ and f/ $\theta$ substitutions are labial assimilation. Labial assimilation occurred coincidently because there happens to be labial sounds in the $\underline{A P P}-R$ target words that contain a final $/ \theta /$. None of the subjects used other labial assimilations .

secondly, some phonological processes may only occur in specific phonemic environments in BE dialect, and this environment does not exist in the target words of the APP-R. An example of this is that BE speakers also change medial and final $/ \theta /$ to $/ E /$ in words that do not contain labial sounds, e. g., ruf/rue (Ruth) and tif/tio (teeth). In these two examples, place shift, but not labial assimilation, occurs. This sound change appears to be random, despite the fact that the occurrences of labial assimilation and place shift were statistically significant. "Toothbrush" and "mouth" are the target words with medial and final $/ \theta /$. Of the 15 BE speakers in this study, 6 (40\%) of them did not make this substitution in either of the target words; $3(20 \%)$ made the substitution in "mouth" only; $3(20 \%)$ made the substitution in "toothbrush" only; and 3 (20\%) made the 
substitution in both target words.

Thirdly, phonological processes may be more likely to occur in connected speech. Since the responses for the $\underline{A P P-R}$ consist of one-word utterances, this test would not show these speech patterns. A sample of connected speech would likely give the most accurate sample of sound changes that are distinctive to an individual and to a dialect. It may have been more meaningful to use a phonological test that requires connected speech for this study.

Fourth, the subjects in this study were between the ages of 8 and 10 years old. This means that they would have been in the school setting for 4 to 5 years. They were, no doubt, familiar with testing environments, an environment that generally include standard English especially if the tester is white, as was the case in this study. Children this age may not be cognizant of the practice of code switching, but many of the children in this study did code switch nonetheless. The researcher noticed this during the data collection. When walking with the child from the classroom to the testing room, she and the child talked. on several occaslons, though not all, the researcher noticed that the child was speaking in BE dialect during this chat, but switched to SE for many of the test responses. It may be that preschool-aged children would not code switch when they are in a similar 
situation. Hence, if this research were done on preschoolers, the results could be quite different. If this were so, the results of this research may have been different if the subjects were preschool-aged children.

Fifth, the subjects for this study attended an integrated school. The BE speakers may mix SE dialect with their own dialect because they hear standard English from their friends and classmates. BE speakers in a segregated school may use more phonological processes because they do not communicate with SE speakers as frequently as those children in an integrated school.

Sixth, the five predicted phonological processes that did not occur, 1. e., syllable reduction, stopping, alveolar assimilation, postvocalic devoicing, and deficlency of liquid / $/$ / in the medial position, may not, in fact, occur in Portland's BE dialect.

In conclusion, it is essential that speech-language pahtologists have a working knowledge of the primary dialect of the population that they work with. This knowledge helps to maximixe the effectiveness of assessment measures and intervention stategies. This researcher has postulated six possible factors that contributed to the results of this study. This study can not be described as a norming study because of the limited number of subjects and their specific age range. However, the data collected can serve as the preliminary data that 
acts as a springboard to further research. 


\section{CHAPTER V}

\section{SUMMARY AND IMPLICATIONS}

\section{SUMMARY}

Black English ( $B E)$ is a rule-governed linguistic system with its own phonology, syntax, semantics, and pragmatics. BE is a dialect, not a disordered variation of standard English (SE). When compared to $S E$, BE phonology has been described in terms of omissions, substitutions, and additions. This study looked at normal BE speakers in Portland, oregon and described their dialectal differences in terms of phonological processes.

Phonological process analysis has become a salient mode of articulation assessment. Phonological processes are the systematic sound changes that affect an entire class of sounds or sound sequences. They often occur as a normal part of the phonology of several dialects of American English. The purpose of this study was to compare the types and frequencies of occurrence of phonological processes, when formally evaluated. The phonological processes that normal BE speakers use must be identified in order that a speech-language pathologist can determine if the speech of a $B E$ speaking child deviates from the dialectal norms. 
The experimental group consisted of 15 BE speakers and the control group consisted of $20 \mathrm{SE}$ speakers. All subjects were between 8.3 and 10.9 years of age, had normal hearing, and lacked a phonetic articulation disorder or delay, and attended the same integrated school in Portland. The Assessment of Phonological Processes-Revised (APP-R) (Hodson, 1986) was administered to both groups. The Computer Analysis of Phonological Processes (CAPP) (Hodson, 1985) was applied for the ten basic processes specified by Hodson. A manual analysis was done on the other 26 phonemic substitutions, assimilations, voicing alterations, and place shifts.

The mean occurrences of the phonological processes used by the BE group were compared with those used by the SE group via two-tailed t-tests for independent means. The results of this study showed that the normal BE subjects used 8 of the 36 phonological processes significantly more frequently than the SE subjects. These phonological processes were consonant sequence reduction, postvocalic singleton deficiency, strident deficiency, velar obstruent deficiency, liquid /l/ deficlency, nasal deficiency, vowelization, labial assimilation, and place shifts. Although not significantly, some BE speakers used liquid /r/deficiency, stopping, and palatalization while some SE speakers used prevocalic singleton deficiency and prevocalic volcing. 
Possible reasons that the results were somewhat different than expected are: 1) phonological processes may occur only in specific phonemic environments in BE; 2) phonological processes may more likely occur in connected speech; 3) most of the $B E$ speakers may have code switched;

4) the BE subjects attended an integrated school and therefore more likely use some $S E ;$ 5) some phonological processes may not occur in Portland's BE dialect.

The CAPP (Hodson, 1985) did not identify any of the BE speakers in this study as having a phonological disorder. Even though they used eight phonological processes more frequently than SE speakers, these processes were not used frequently enough to be targeted for phonological intervention. This would indicate that the APP-R is an approprlate assessment to use with older BE speaking children in Portland, Oregon because with this test their dialectal differences are not frequent enough to warrant the label of disordered or delayed.

\section{IMPL I CATIONS}

$\underline{\text { Research }}$

Further research regarding $B E$ dialects is warranted; there is a dearth of information about phonological development and normal adult phonology of BE speakers. Several tests can be used to gather information; the $\underline{A P P}-R$ is but one of them. A study to determine phonological 
processes of $B E$ speakers, using an assessment instrument that looks at phonology in connected speech would be appropriate. It would be especially interesting to compare the results of such an assessment with the results of the APP-R for the same sample.

It would be of interest to determine if the results of this study would be different if the BE subjects attended a segregated school. These subjects would be less familiar with standard English and/or less likely either to code switch or to be bidialectal.

The results of this study cannot be applied to all BE speakers in this country because BE dialect, like all dialects, is regional. Replication of this study in a different geographic (from Portland, Oregon) area would be of interest to a speech-language pathologist.

Clinical

within Portland, oregon it may not be valid to apply these results to $\mathrm{BE}$ speakers who attend segregated schools. These students may not code switch because of their lack of contact with SE speakers, which leads to a lack of familiarity with standard English.

A clinician testing a child whose primary dialect is $\mathrm{BE}$ should be aware of the occurrence of code switching. This phenomenon may be more crucial when a clinician is attempting to determine dialectal differences or establish dialect norms. It is probable that young school aged 
children are not aware of it, if/when they do code switch. The nuances of $B E$ dialect are regional; therefore, the information acquired from this research only applies to BE speakers in Portland, oregon. A speech-language pathologist working in a different area of the country would be well-advised to determine the phonological patterns of $B E$ speakers in the area.

The results of this study may help a speech-language pathologist to determine if the phonology of a BE speaker deviates from the dialectal norms. Although norms cannot be established on as small a sample as was used for this research, this study does note the phonological patterns that occur with significantly more frequency in normal $B E$ speakers that in normal SE speakers and those processes whose occurrences are not significantly different.

A statement in regards to the suitability of the APP-R for $B E$ speakers is warranted. Analysis of the first ten phonologlcal processes was done with the CAPP, (Hodson, 1985) whlch determined that all of the subjects in both groups were not candidates for a phonological approach. One of the results of the computer analysis is a statement regarding whether or not the testee is a candidate for a phonological treatment approach (Appendix D), 1. e., if the child has a phonological disorder warranting intervention. Additionally, when the 
child is a candidate for this approach the CAPP lists the phonological processes that need to be suppressed.

Consequently, it would appear that the $\underline{A P P-R}$ is an approprlated test to give to $\mathrm{BE}$ speakers, of 8 years of age or older, in Portland, oregon because none of the normal $B E$ speakers in this sample were dlagnosed as having a phonological processes disorder. However, speech-language pathologists should not merely accept this statement and proceed blindly. They need to use their clinlcal judgement when using the APP-R with this population. The data collected in this study lead to the following recommendations. If the CAPP for a BE speaker were to state that the child did have a phonological disorder, the clinician likely should not intervene with any of the phonological processes that this research shows to occur significantly more frequently with BE speakers when compared with SE speakers. Speech-language pathologists will likely want to intervene with processes that occurred with less than a statistically significant frequency. Speech-language pathologists should intervene with phonological processes that none of the $B E$ speakers used because these processes are not intrinsic to $\mathrm{BE}$ phonology. It follows that clinicians use these guidelines when determining a child's candidacy for the 20 phonological processes that are scored manually. speech-language pathologists need to integrate these 
recommendations with both their clinical judgement and a working knowledge of $B E$ dialect. 
REFERENCES

Adler, S. (1971). Dialectical differences: professional and clinical implications. Journal of Speech and Hearing Disorders, 36, 90-110.

Adler, S. (1979). Poverty ch1ldren and their language: implications for teaching and treating. New York: Grune \& stratton, Inc.

Adler, S., \& Whitman-Tim, I. A. (1980). The pediatric language specialist: an innovative approach to early language intervention and the role of the speech-language clinician. Speech and Language: Advances in Basic Research and Practice, $\underline{3}, 99-127$.

Bliss, L., \& Allen, D. (1983). Screening Kit of Language Development. Baltimore: University Park Press.

Bruning, J. L., \& Kintz, B. L. (1987). Computational handbook of statistics (3rd ed.). Glenview, IL: scott, Foresman and Company.

D1llard, J. L. (1972). Black English. New York: Random House.

Hodson, B. (1986). Assessment of Phonological

Processes-Revised. Danvilie: Interstate Printers \& Publishers, Inc.

Hodson, B. (1985). Computer analysis of phonological processes. [Computer program]. Stonington, Illinois: Phonocomp.

Ingram, D. (1976). Phonologlcal disability in children. New York: Elsevier.

Khan, L., \& Lewis, N (1986). Khan-Iewis Phonological Analysis. Circle Pines, MN: American Guidance Service, Inc.

Ma1lory, Y. \& Chapman, D. L. (1978). Sequential features of child Black English. Language, Speech and Hearing Services in Schools, $9,204-209$.

Meitus, I. J. \& We inberg, B. (1983). Diagnosis in speech-language pathology. Austin: pro-Ed. 
Nelson, N. (1983). Black English sentence scoring: A tool for non-biased assessment. paper presented at the Annual Convention of American

Speech-Language-Hearing Association, Cincinnati. In

o. L. Taylor (Ed.), Nature of communication

disorders in culturally and linguistically diverse populations. San Diego: College-Hill Press.

Nicolosi, L. Harryman, E. \& Kreshock, J. (1989). Terminology of communication disorders:

Speech-language-hearing (3rd ed.). Baltimore: Williams \& wilkins.

Seymour, H. N. \& Miller-Jones, D. (1981). Language and cognitive assessment of Black children. Speech and Language: Advances in Basic Research and Practice, $\underline{6}$, 203-263.

Seymour, H. N., \& Seymour, C. M. (1981). Black English and standard American English contrasts in consonant development of four and five-year old children. Journal of Speech and Hearing Disorders, 46 , 274-280.

Shames, G. H. \& Wiig, E. H. (1986). Human communication disorders (2nd ed.). Columbus: Charles E. Merrill Publishing Company.

Shriberg, L. \& Kwiatkowski, J. (1980). Natural process analysis (NPA). New York: John Wiley.

Smitherman, G. (1977). Talkin' and testifyin': the language of Black America. New York: Houghton Mifflin.

Vaughn-Cooke, F. B. (1983). Improving language assessment in minority children. ASHA, 25, 29-34.

Weddington, G. T. (1987). Communication disorders among African American: Update 1987. Paper presented at California state University, Hayward.

Weiner, F. F. (1979). Phonological process Analysis. Baltimore: University Park Press.

Weiss, C. E., Gordon, M. E., \& Lillywhite, H. S. (1987). Clinical management of articulatory and phonological disorders. Baltimore: Williams \& Wilkins.

Werner, E. O., \& Kresheck, J. D. (1983). Structured Photographic Expressive Lanquage Test-Preschool. Sandwich, Illinois: Janelle Publications, Inc. 
APPENDIX A

CONSENT FORM FOR SUBJECTS

AND CONTROLS 
Dear Parent,

My name is Eileen Rella and I am a graduate student in speech and Hearing Sciences at Portland State University. I am conducting a study of the speech sounds of eight, nine, and ten year old children. I would like permission for your child to be one of the speakers in the study.

In this study, I will test each student's hearing, then each student will verbally identify a series of pictures; this vill be tape recorded so that I can listen to the speech sounds again. Your child will be able to name all of these pictures in about fifteen minutes.

I will be supervised by Mary E. Gordon, Associate Professor at Portland State University. Your child's name will not be used in the study. You may withdraw your child from this study at any time without jeopardizing your relationship with Portland state University.

Please check below and return this to your chlld's classroom teacher. Thank you for your time and cooperation.

study.

Yes, may take part in this

$$
\text { (Child's full name) }
$$

No, I do not want my child to take part in this study.

Signature of parent or guardian

Date

Child's full date of birth

If you experience problems that are the result of your participation in this study, please contact the secretary of the Human subjects research and Review Committee, office of Grants and Contracts, 303 Cramer Hall, Portland State University, P. O. Bos 751, Portland, OR 97207. The phone number is $464-3417$. 


\section{APPENDIX B}

CONSENT FORM FOR SUBJECTS OVER

SEVEN YEARS OF AGE 
Dear student,

My name is Eileen Rella and I am a graduate student in Speech and Hearing sciences at portland State University. I am doing a study of speech sounds of eight, nine and ten year old children. I would like permission for you to be one of my subjects (students).

In this study I will test your hearing. Then I will ask you to tell me the name of objects and pictures; this will be tape recorded so that I can listen to your sounds again if I need to. You will be able to name all the objects and pictures in about fifteen minutes.

Mary Gordon is my teacher at portland State University and she will supervise me. Your name will not be used in this study. You may change your mind about doing this at any time and no one will be angry will you.

Please return this to your classroom teacher. Thank you for your cooperation and time.

study.

will take part in this

(Child's full name)

signature of child

Date

Child's full date of bieth

If there are any problems as a result of your being part

of this study, please call 464-3417 and ask to speak to

the secretary of the Human subjects Research and Review Committee. The address is offlce of Grants and contracts, 303 Cramer Hall, Portland state University, P. O. Box 751, Portland, Oregon 97207. 
APPENDIX C

CONSENT FORM FOR RELIABILITY SAMPLE 
Dear Parent,

My name is Eileen Rella and I am a graduate student in speech and Hearing Sciences at Portland State University. I am conducting a study of the speech sounds of eight, nine, and ten year old children and I need to make comparisons with four and five year olds. I would like permission for your child to be one of the speakers in the study.

In this study, I will test each child's hearing, then each child will verbally identify a series of pictures; this will be tape recorded so that I can listen to the speech sounds again. Your child will be able to name all of these pictures in about fifteen minutes.

I will be supervised by Mary E. Gordon, Associate Professor at Portland State University. Your child's name will not be used in the study. You may withdraw your child from this study at any time without jeopardizing your relationship with Portland state University.

Please return this to your child's classroom teacher. Thank you for your time and cooperation.

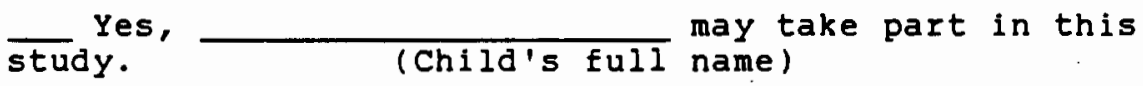

_ No, my child may not take part in this study.

$\overline{\text { Signature of parent or guardian }}$

Date

Child's full date of birth

If there are any problems as a result of your being part of this study, please call 464-3417 and ask to speak to the secretary of the Human subjects Research and Review Committee. The address is office of Grants and contracts, 303 Cramer Hall, Portland state University, P. O. Bos 751, Portland, OR 97207 . 
APPENDIX D

ASSESSMENT OF PHONOLOGICAL PROCESSES :

ANALYSIS OF PHONOLOGICAL PROCESSES 


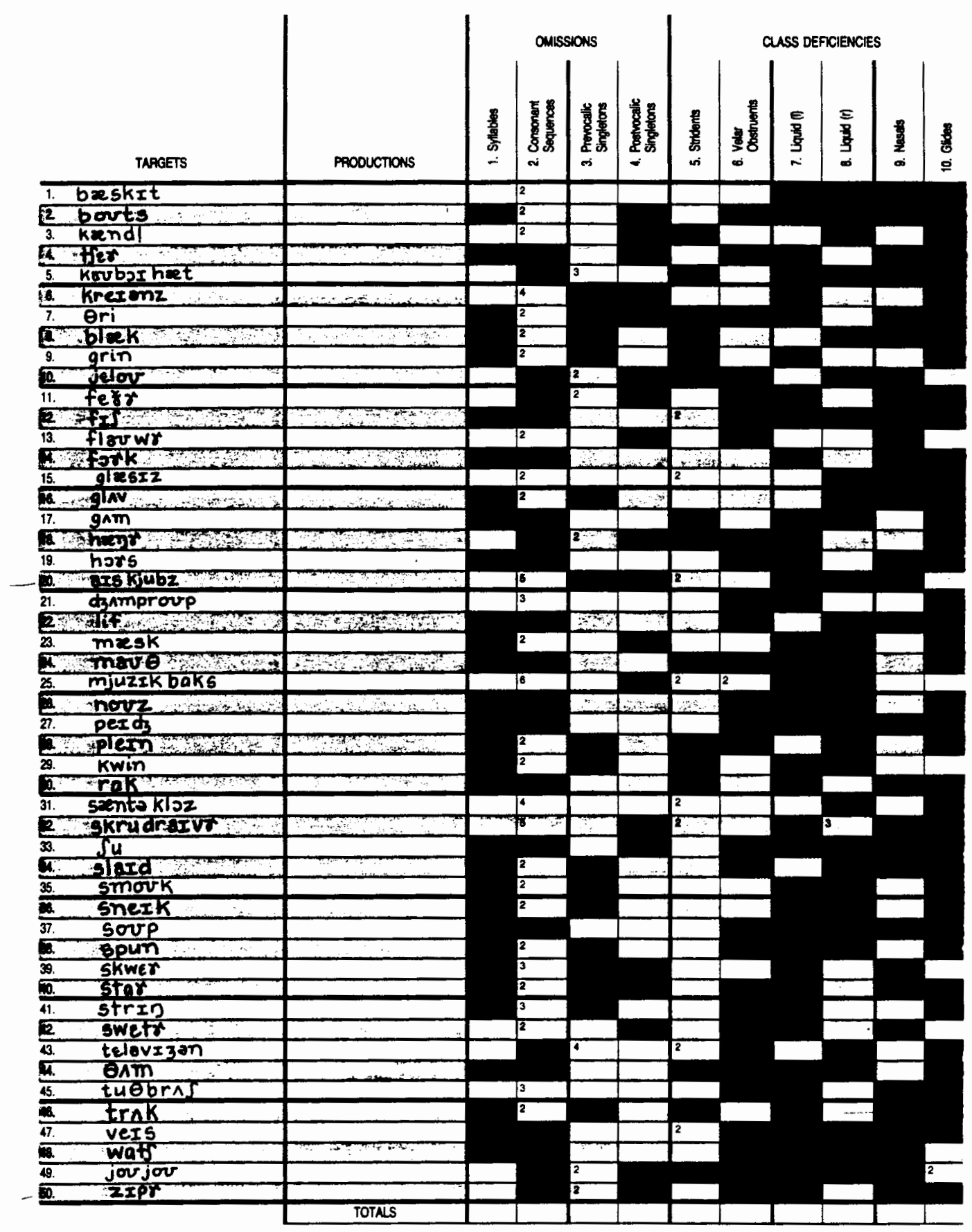




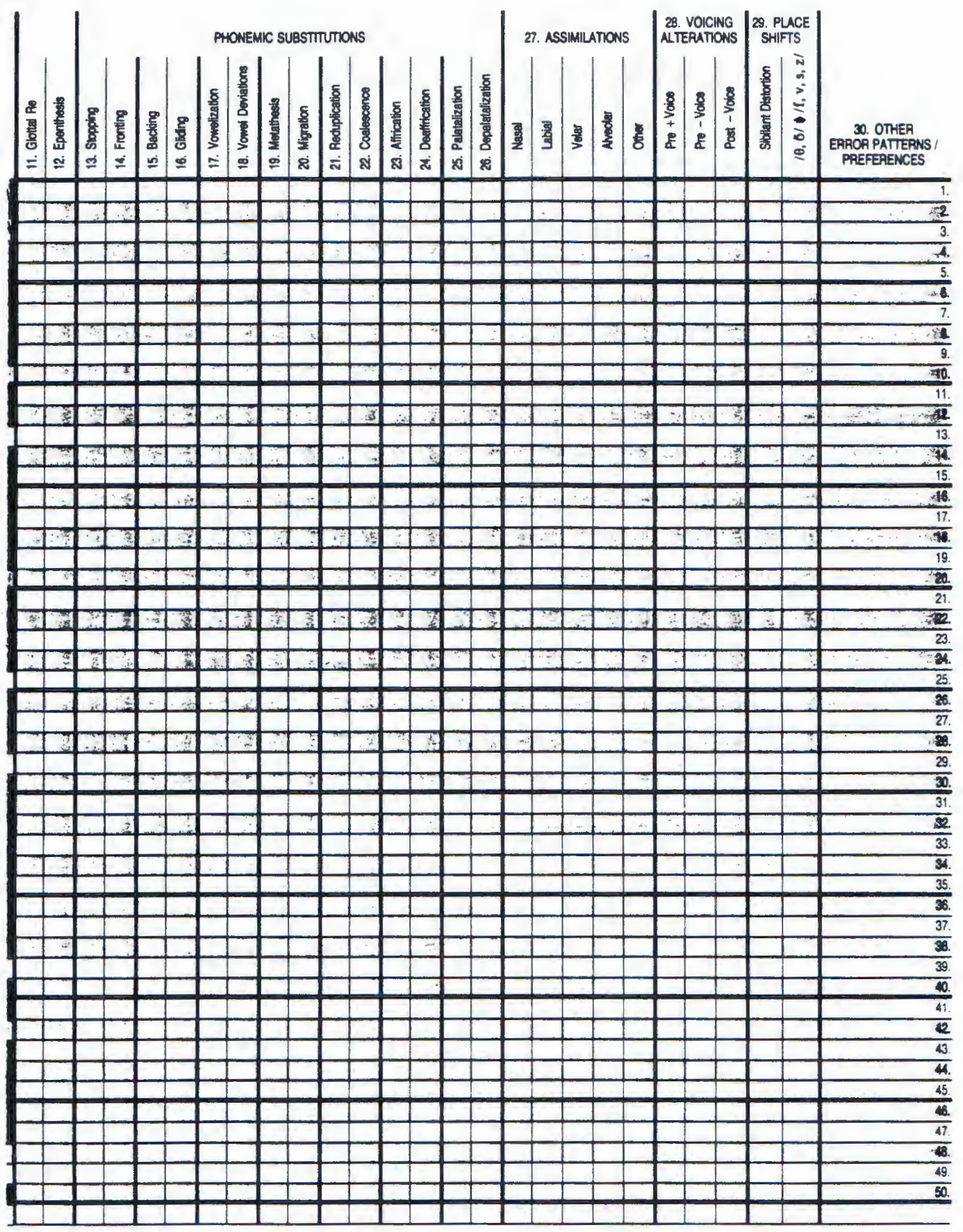




\section{APPENDIX E}

COMPUTER ANALYSIS OF PHONOLOGICAL PROCESSES 


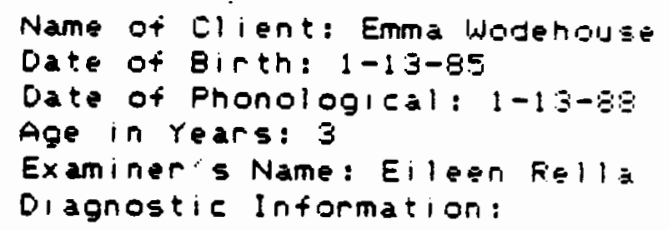

Phariologizal Arialysis Summary

Patterri Deyiatians

Percentage ot

Sy|1.able Fe-10

Prevoealie Singistans

vecurrenge

Postuocalie singletons

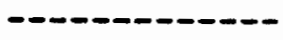

Consonant bequences

0

0

Stridents

Velars

Liquid (i)

0

0

0

Liquid (

Liquid 6

Nasals

G) I des

0

0

0

0

0

Average of Phoriglogical Processes: 0

This elient is not a candidats for phonologieal appriser.

COMPLITEF APHALYSIS OF PHONOLOGICAL PFOCESSES

Barbara Williams Hodson

Coprrignt i?g5; Phonocomp 